\title{
A Study on Abdominal Obesity at Basra University Staffs
}

\author{
Sajjad S. Issa $^{1,}$, Samira M. Ibrahim², Abdulameer A. Al-Mussawi ${ }^{3}$ \\ ${ }^{1}$ Community Medicine, Department of Basics of Nursing, College of Nursing, University of Basrah, Basrah, Iraq \\ ${ }^{2}$ Community Medicine, Department of Basic Medical Sciences, College of Nursing, University of Basrah, Basrah, Iraq \\ ${ }^{3}$ General Surgery, Department of Basic Medical Sciences, College of Nursing, University of Basrah, Basrah, Iraq
}

\section{Email address:}

sajjad.issa@uobasrah.edu.iq (S. S. Issa),samira.ibrahim@uobasrah.edu.iq (S. M. Ibrahim), abdulameer.yaqoop@uobasrah.edu.iq (A. A. Al- Mussawi)

${ }^{*}$ Corresponding author

\section{To cite this article:}

Sajjad S. Issa, Samira M. Ibrahim, Abdulameer A. Al-Mussawi. A Study on Abdominal Obesity at Basra University Staffs. Clinical Medicine Research. Vol. 6, No. 3, 2017, pp. 69-73. doi: 10.11648/j.cmr.20170603.12

Received: February 3, 2017; Accepted: March 3, 2017; Published: March 27, 2017

\begin{abstract}
A descriptive cross- sectional study was designed involving Basra university staff for the study of abdominal obesity. The university of Basra had two location: karmet Ali (108 samples ) and Bab Alzubiar (158 samples ), A randomly selected sample was taken from a list of the college, from the selected college we were chosen staff randomly. The total number of the selected college was 10, were all the departments in that colleges was included and the total number selected of staff was 266, from them were females 146 and 120 males. The demographic data has been obtained from each person in the study, The working team was asked to measure the height, weight, waist circumference and Random Blood Sugar for each selected sample, using a weight and height scale, tape measure and portable blood sugar measurement instrument.(SPSS), Version 17 was utilized for the purpose for statistical analysis of the data. The results was $45 \%$ was males and $55 \%$ was females, BMI: $19.5 \%$ had healthy weight, $36.8 \%$ were overweight, 27.8 were obese, $12 \%$ were severely obese, $3.8 \%$ were morbidly obese, $43.6 \%$ of the sample were obese. $37.5 \%$ of the males were obese and $48.63 \%$ of the females were obese. $30.8 \%$ carried positive history of obesity and $36.8 \%$ of the sample was practicing sport exercise, $87.6 \%$ were having normal blood sugar while $12.4 \%$ were having abnormal blood sugar (diabetics), $18 \%$ of the females had normal waist circumference and $47.5 \%$ of the males had normal waist circumference, that is mean $87 \%$ of the female had abdominal obesity and $52.5 \%$ of the males had abdominal obesity. The prevalence of abdominal obesity was $31.57 \%$, high significant correlation between waist circumference and gender, significant correlation between BMI and practicing exercise and there is highly significant correlation between BMI and positive history of obesity in the family. high significant relationship between body weight and waist circumference and high significant relation between waist circumference and history of obesity, significant relation between waist circumference and number of daily meals and high significant relation between waist circumference and random blood sugar.
\end{abstract}

Keywords: Obesity, Abdominal, University Staffs

\section{Introduction}

\subsection{Introduction}

The most basic definition of overweight and obesity is having too much body fat-so much so that it "presents a risk to health." [1] A reliable way to determine whether a person has too much body fat is to calculate the ratio of their weight to their height squared. This ratio, called the body mass index (BMI), accounts for the fact that taller people have more tissue than shorter people, and so they tend to weigh more. BMI uses a simple calculation based on the ratio of someone's height and weight $\left(\mathrm{BMI}=\mathrm{kg} / \mathrm{m}^{2}\right)$. Research has shown that BMI is strongly correlated with the gold-standard methods for measuring body fat. [2]

Healthy BMI in Adults

The World Health Organization (WHO) states that for adults, the healthy range for BMI is between 18.5 and 24.9. Overweight is defined as a body mass index of 25 to 29.9, and obesity is defined as a body mass index of 30 or higher. 


\section{[1]}

\section{Waist Size Matters: Abdominal Obesity}

One important category of obesity not captured by BMI is so-called "abdominal obesity" - the extra fat found around the middle that is an important factor in health, even independent of BMI. The simplest and most often used measure of abdominal obesity is waist size. Guidelines generally define abdominal obesity in women as a waist size 35 inches or higher, and in men as a waist size of 40 inches or higher.

\section{Measuring Body Fat}

There are a number of ways to measure body fat. Some are well suited to the doctor's office, such as calculating a person's BMI. Other, more complex methods require specialized equipment, such as magnetic resonance imaging or dual energy X-ray absorptiometry machines; while these machines can measure body fat very accurately, they are typically only used for this purpose in research settings.

Globally, there are 1.5 billion adults who are either overweight or obese, a number expected to increase to 3 billion by 2030. The epidemic is reaching catastrophic proportions, and one of the key-if small — steps to bringing it under control is to have a common language to describe the problem Worldwide, an estimated 1.5 billion adults over the age of 20-about 34 percent of the world's adult population-are overweight or obese. [3] By 2030, this is expected to rise to more than 3 billion people. [4] For clinical and research purposes, obesity is divided into three categories: Class I (30-34.9), Class II (35-39.9) and Class III (40). [5] With the growth of extreme obesity, researchers and clinicians have further divided Class III into super-obesity (BMI 50-59) and super-super obesity (BMI60).

Risk of developing health problems, including several chronic diseases such as heart disease and diabetes, rises progressively for BMIs above 21. [5] So does the risk of dying early. $[6,7]$

\section{How Abdominal Fat Increases Disease Risk}

Fat around the midsection is a strong risk factor for heart disease, type 2 diabetes, and even some types of cancers [8]long-term follow-up studies showed that so-called "abdominal obesity" was strongly associated with an increased risk of type 2 diabetes, cardiovascular disease and death, even after controlling for body mass index (BMI). [9, 10]

Abdominal Obesity Measurement Guidelines

Table 1. Abdominal Obesity Measurement Guidelines.

\begin{tabular}{|c|c|c|}
\hline Organization & Measurement used & Definition of abdominal obesity \\
\hline $\begin{array}{l}\text { American Heart Association, National Heart, Lung and Blood } \\
\text { Institute [11] }\end{array}$ & Waist circumference & Women: $>88 \mathrm{~cm}$ (35 inches), Men: $>102 \mathrm{~cm}$ (40 inches) \\
\hline International Diabetes Federation [12] & Waist circumference & $\begin{array}{l}\text { Women: }>80 \mathrm{~cm} \text { ( } 31.5 \text { inches }), \text { Men: }>90 \mathrm{~cm}(35.5 \\
\text { inches)Different cut-points for different ethnic groups }\end{array}$ \\
\hline World Health Organization [13] & Waist-to-hip ratio & Women: $>0.85$, Men: $>0.9$ \\
\hline
\end{tabular}

The table showed the limit of the measures of waist circumference and waist hip ratio according to WHO, American Heart Association, National Heart, Lung and Blood Institute and International Diabetes Federation

\subsection{Importance of the Study}

Obesity among adult has become a major public health problem in developed and developing countries, including Iraq. With wide range of adverse outcomes of include psychological and physical effects and obesity is a major risk factor for cardiovascular diseases, diabetes, hypertension and cancers.

\subsection{The Objectives of the Study}

1-To estimate the prevalence of obesity and abdominal obesity in Basra university staff, defined by body mass index (BMI) and waist circumference measures according to American Heart Association.

2-To identify any variation as per age gender.

3-To identify any correlation between obesity and abdominal obesity versus Body mass index (BMI), Random Blood Sugar, No. of daily meals, practicing sport exercise, Monthly income and Family history of obesity.

\section{Methodology}

\subsection{Methodology}

\subsubsection{Study Setting and Population}

A descriptive cross- sectional study was designed involving Basra university staff, for the study of abdominal obesity.

\subsubsection{The Study Sample and Data Collection}

The university of Basra had two location

1- karmet Ali (108 )2- Bab Alzubiar (158)

Each location is composed of a number of colleges. The investigators had visited the two locations. A randomly selected sample was taken from a list of the college, from the selected college we were chosen staff randomly.

The total number of the selected college was 10 , were all the departments in that colleges was included and the total number selected of staff was 266 , from them were females 146 and 120 males.

\subsubsection{The Studied Variables}

Age: 23 - 66, Gender: males and females, Level of education, Weight: in kilogram

Height: in meter, Body mass index (BMI): according to 
WHO chart waist circumference, Random Blood Sugar, No. of daily meals, practicing sport exercise: yes or no, Monthly income: enough or not enough, Family history of obesity: yes or no

\subsubsection{The Tools}

The working team was asked to measure the height, weight, waist circumference and Random Blood Sugar for each selected sample, using a weight and height scale, tape measure and portable blood sugar measurement instrument. The team used a designed forma for the propose of the study which include information related to the variables as shown in (appendix?)

\subsubsection{Statistical Analysis}

The Statistical Package for Social Science (SPSS), Version 17 was utilized for the purpose for statistical analysis of the data. The statistical measures was in form of frequencies, percentages, and Pearson correlation

\section{Results}

Table 2. Distribution of the sample according to demographic characteristics.

\begin{tabular}{lll}
\hline Item & Frequency & \% \\
\hline Location & & \\
Karmetali & 108 & 40.6 \\
Bab Alzubair & 158 & 59.4 \\
Gender & & \\
Male & 120 & 45.1 \\
Female & 146 & 54.9 \\
Level of education & & \\
Primary & 7 & 2.6 \\
Intermediate & 28 & 10.5 \\
Secondary & 31 & 11.7 \\
Diploma & 30 & 11.3 \\
Bachelor & 75 & 28.2 \\
Master & 38 & 14.3 \\
Doctorate & 57 & 21.4 \\
Total & 266 & 100 \\
\hline
\end{tabular}

The total sample was $266,40.6 \%$ (108) was from karmetali while 59.4\% (158) from Bab Alzubair location. $45.1 \%$ was males and $54.9 \%$ was females. $2.6 \%$ had primary school graduation, $10.5 \%$ had intermediate schools graduation, $11.7 \%$ secondary school graduation, $11.3 \%$ diploma graduation, $28.2 \%$ bachelor graduation, $14.3 \%$ master degree, $21.4 \%$ doctorate degree

Table 3. Distribution of the sample according to age interval.

\begin{tabular}{llll}
\hline Item & Age interval & Frequency & $\mathbf{\%}$ \\
\hline 1 & $21-30$ & 18 & 6.76 \\
2 & $31-40$ & 91 & 34.2 \\
3 & $41-50$ & 110 & 41.35 \\
4 & $51-60$ & 39 & 14.66 \\
5 & $61-70$ & 8 & 3 \\
& Total & 266 & 100 \\
\hline
\end{tabular}

The table showed that $6.76 \%$ was at first age interval, 34.2 at second age interval, $41.35 \%$ at third age interval, $14.66 \%$ at fourth age interval, $3 \%$ at fifth age interval

Table 4. Distribution of practicing sport exercise.

\begin{tabular}{lll}
\hline practicing sport exercise & Frequency & Percent \\
\hline NO & 168 & 63.2 \\
YES & 98 & 36.8 \\
& 266 & 100.0 \\
\hline
\end{tabular}

The table showed that $36.8 \%$ of the sample was practicing sport exercise

Table 5. Distribution of the history of obesity.

\begin{tabular}{lll}
\hline history of obesity & Frequency & Percent \\
\hline No & 184 & 69.2 \\
Yes & 82 & 30.8 \\
Total & 266 & 100.0 \\
\hline
\end{tabular}

The table showed that $30.8 \%$ carried positive history of obesity

Table 6. Distribution of BMI.

\begin{tabular}{lll}
\hline BMI & Frequency & Percent \\
\hline healthy weight & 52 & 19.5 \\
Overweight & 98 & 36.8 \\
Obese & 74 & 27.8 \\
severely obese & 32 & 12.0 \\
morbidly obese & 10 & 3.8 \\
Total & 266 & 100.0 \\
\hline
\end{tabular}

The table showed that $19.5 \%$ had healthy weight, $36.8 \%$ were overweight, 27.8 were obese, $12 \%$ were severely obese, $3.8 \%$ were morbidly obese. i. e. $43.6 \%$ of the total sample was obese and $36.8 \%$ was overweight

Table 7. Distribution of random blood sugar.

\begin{tabular}{lll}
\hline random blood sugar & Frequency & Percent \\
\hline Abnormal & 33 & 12.4 \\
Normal & 233 & 87.6 \\
Total & 266 & 100.0 \\
\hline
\end{tabular}

The table showed that $87.6 \%$ were having normal blood sugar while $12.4 \%$ were having abnormal blood sugar (diabetics)

Table 8. Distribution of the sample according to the normal waist circumference values (according to American Heart Association) and gender.

\begin{tabular}{llll}
\hline Waist circumference normal values & Frequency & \% & Total \\
\hline Women: less than $88 \mathrm{~cm}$ & 27 & 18 & 146 \\
Men: less than $102 \mathrm{~cm}$ & 57 & 47.5 & 120 \\
Total & 84 & 31.57 & 266 \\
\hline
\end{tabular}

The table showed that $18 \%$ of the females had normal waist and $47.5 \%$ of the males had normal waist circumference, that is mean $87 \%$ of the female had abdominal obesity and $52.5 \%$ of the males had abdominal obesity, and $31.57 \%$ was the abdominal obesity for total sample. 
Table 9. Distribution of obesity according to BMI WHO categories.

\begin{tabular}{lll}
\hline Classification & Frequency & Percent \\
\hline None obese & 150 & 56.4 \\
Obese & 116 & 43.6 \\
Total & 266 & 100.0 \\
\hline
\end{tabular}

The table showed that $43.6 \%$ of the sample were obese and $56.4 \%$ were none obese

Table 10. Distribution of obesity(according to BMI WHO categories) by gender.

\begin{tabular}{llllll}
\hline & None obese & & Obese & & \\
\hline Gender & Frequency & \% & Frequency & Frequency & Frequency \\
\hline Males & 75 & 62.5 & 45 & 45 & 45 \\
Females & 75 & 51.37 & 71 & 71 & 71 \\
Total & 150 & & 116 & 116 & 116 \\
\hline
\end{tabular}

The table showed that $37.5 \%$ of the males were obese and $48.63 \%$ of the females were obese.

Table 11. Correlation between BMI and practicing exercise and history of obesity.

\begin{tabular}{lll}
\hline $\begin{array}{l}\text { Pearson Correlation } \\
\text { BMI }\end{array}$ & $\begin{array}{l}\text { practicing sport } \\
\text { exercise }\end{array}$ & history of obesity \\
\hline Sig. (2-tailed) & $-0.150-^{*}$ & $0.236^{* *}$ \\
N & .014 & .000 \\
& 265 & 265 \\
\hline
\end{tabular}

The table showed that there is significant correlation between BMI and practicing exercise and there is highly significant correlation between BMI and positive history of obesity in the family.

Table 12. Correlation between body weight and waist circumference.

\begin{tabular}{llll}
\hline & & & \\
\hline & & body weight & waist circumference \\
\hline \multirow{2}{*}{ body } & Pearson Correlation & 1 & $0.764^{* *}$ \\
weight & Sig. (2-tailed) & & .000 \\
& $\mathrm{~N}$ & 266 & 266 \\
\hline
\end{tabular}

The table showed that there is high significant relationship between body weight and waist circumference.

Table 13. Correlation between waist circumference and history of obesity.

\begin{tabular}{|c|c|c|c|}
\hline \multicolumn{4}{|l|}{ Correlations } \\
\hline & & $\begin{array}{l}\text { waist } \\
\text { circumference }\end{array}$ & $\begin{array}{l}\text { history of } \\
\text { obesity }\end{array}$ \\
\hline \multirow{3}{*}{$\begin{array}{l}\text { waist } \\
\text { circumference }\end{array}$} & Pearson Correlation & 1 & $.211^{* *}$ \\
\hline & Sig. (2-tailed) & & .001 \\
\hline & $\mathrm{N}$ & 266 & 266 \\
\hline
\end{tabular}

The table showed that there is high significant relation between waist circumference and history of obesity.

Table 14. The correlation between waist circumference and number of daily meals.

\begin{tabular}{llll}
\hline Correlations & & waist & No. of daily \\
& & circumference & $\begin{array}{l}\text { meals } \\
\text { meals }\end{array}$ \\
\hline \multirow{2}{*}{ waist } & Pearson Correlation & 1 & $.136^{*}$ \\
circumference & Sig. (2-tailed) & & .027 \\
& $\mathrm{~N}$ & 266 & 266 \\
\hline
\end{tabular}

The table showed that there is significant relation between waist circumference and number of daily meals.

Table 15. The correlation between waist circumference random blood sugar.

\begin{tabular}{llll}
\hline Correlations & & & \\
\hline & & $\begin{array}{l}\text { waist } \\
\text { circumference }\end{array}$ & $\begin{array}{l}\text { random } \\
\text { blood sugar }\end{array}$ \\
\hline & Pearson Correlation & 1 & $.191^{* *}$ \\
$\begin{array}{l}\text { waist } \\
\text { circumference }\end{array}$ & Sig. (2-tailed) & & .002 \\
& $\mathrm{~N}$ & 266 & 266 \\
\hline
\end{tabular}

The table showed that there is high significant relation between waist circumference and random blood sugar.

Table 16. The correlation between waist circumference and gender.

\begin{tabular}{llll}
\hline Correlations & & $\begin{array}{l}\text { gender of } \\
\text { sample }\end{array}$ & $\begin{array}{l}\text { waist } \\
\text { circumference }\end{array}$ \\
\hline & & 1 & $-.213^{* *}$ \\
gender of sample & $\begin{array}{l}\text { Pearson } \\
\text { Correlation }\end{array}$ & 1260 \\
& Sig. (2-tailed) & & .000 \\
& $\mathrm{~N}$ & 266 & 266 \\
\hline
\end{tabular}

The table showed that there is high significant correlation between waist circumference and gender.

\section{Discussion}

Our study found that the prevalence of obesity was $43.6 \%$, and $37.5 \%$ of the males were obese and $48.63 \%$ of the females were obese, which is had some difference from a study done in India where they found that the prevalence of obesity was $45.9 \%$, (women: $47.4 \%$; men: $43.2 \%$ ) [14], also in our study we found that $87 \%$ of the female had abdominal obesity and $52.5 \%$ of the males had abdominal obesity, the prevalence of abdominal obesity was $31.57 \%$. while Indian study found that of abdominal obesity was $46.6 \%$ (women: $56.2 \%>$ men: $35.1 \%$,) [14] study done Sri lank found that prevalence of overweight, obesity and abdominal obesity (high WC) were 33.2\% (male 27.3\%/female 38.7\%), 14.3\% (male $9.2 \%$ /female $19.2 \%$ ) and $33.6 \%$ (male $17.7 \% /$ female $49.0 \%$ ) respectively. [15] which is similar to our finding to some extent. our study differ from a study done Spain where all the values of obesity and abdominal obesity is less $(16.6 \%$ in males and $15.2 \%$ in females ) [16]

also Iran study had less prevalence of obesity (34.8\%)and less abdominal obesity (28.3) but it is similar to our study in that female had higher prevalence of abdominal obesity than males [17] Netherlands study showed very low prevalence of obesity in compared to our study, it was 4 and $6 \%$ in men and women, respectively [18]

\section{Conclusions}

1 - the prevalence of obesity among Basra university staff is $43.6 \%$

2- obesity is higher in females compared to males, where $37.5 \%$ of the males were obese and $48.63 \%$ of the females 
were obese

3- $12.4 \%$ of the Basra university staff were having abnormal blood sugar (diabetics)

4- Abdominal obesity is more is females as compared with females, where mean $87 \%$ of the female had abdominal obesity and $52.5 \%$ of the males had abdominal obesity. The prevalence of abdominal obesity was $31.57 \%$

5 - we find that there is high significant correlation between waist circumference and gender for the Basra university staff

6- The WHO categories of BMI in Our staff was as the following

a-healthy weight $=19.5 \%$

b-overweight $=36.8 \%$

c-obese $=27.8$

d-severely obese $=12 \%$

e-morbidly obese $=3.8 \%$

\section{Recommendations}

1- increase and improve opportunities for Basra university staff to engage in physical activity and eat a healthy diet.

2- university authority should allow for all staff to engage in at least 30 minutes of moderate to vigorous physical activity at early morning when the staff started their first hour of work.

3- Educational programs about obesity and associated health consequences should start early in university so as to prevent the increasing prevalence of obesity.

4- specialeducational practical program about obesity designed, instructed, and presented to the obese particularly and people in general. Including information about obesity such as; definition, causes, risk factors and management.

\section{References}

[1] World Health Organization. Obesity and overweight. Fact sheet Number 311. September 2006. Accessed January 25, 2012.

[2] Gallagher D, Visser M, Sepulveda D, Pierson RN, Harris T, Heymsfield SB. How useful is body mass index for comparison of body fatness across age, sex, and ethnic groups? Am J Epidemiol. 1996; 143:228-39.

[3] Finucane MM, Stevens GA, Cowan MJ, et al. National, regional, and global trends in body-mass index since 1980: systematic analysis of health examination surveys and epidemiological studies with 960 country-years and $9 \cdot 1$ million participants. Lancet. 2011; 377:557-67.

[4] Kelly T, Yang W, Chen CS, Reynolds K, He J. Global burden of obesity in 2005 and projections to 2030 . Int.J.Obes. (Lond). 2008; 32:1431-7.

[5] James WPT, Jackson-Leach R, Ni Mhurchu C, et al. Chapter 8: Overweight and obesity (high body mass index). In: Ezzati
M, Lopez AD, Rodgers A, Murray CJL, eds. Comparative quantification of health risks: Global and regional burden of disease attributable to selected major risk factors. Geneva: World Health Organization. 2004.

[6] Adams KF, Schatzkin A, Harris TB, et al. Overweight, obesity, and mortality in a large prospective cohort of persons 50 to 71 years old. N Engl J Med. 2006; 355:763-78.

[7] Manson JE, Willett WC, Stampfer MJ, et al. Body weight and mortality among women. N Engl J Med. 1995; 333:677-85

[8] Klein, S. et al. Absence of an effect of liposuction on insulin action and risk factors for coronary heart disease. New England Journal of Medicine. Vol. 350(25): 2549-2557.

[9] Ohlson LO, Larsson B, Svardsudd K, et al. The influence of body fat distribution on the incidence of diabetes mellitus. 13.5 years of follow-up of the participants in the study of men born in 1913. Diabetes. 1985;34:1055-8.

[10] Larsson B, Svardsudd K, Welin L, Wilhelmsen L, Bjorntorp P, Tibblin G. Abdominal adipose tissue distribution, obesity, and risk of cardiovascular disease and death: 13 year follow up of participants in the study of men born in 1913. Br Med J (Clin Res Ed). 1984; 288:1401-4.

[11] Grummer-Strawn LM, Reinold C, Krebs NF. Use of World Health Organization and CDC growth charts for children aged 0-59 months in the United States. MMWR Recomm Rep. 2010; 59:1-15.

[12] Monasta L, Lobstein T, Cole TJ, Vignerová J, Cattaneo A. Defining overweight and obesity in pre-school children: IOTF reference or WHO standard? Obes Rev. 2011; 12:295-300.

[13] Zhang C, Rexrode KM, van Dam RM, Li TY, Hu FB. Abdominal obesity and the risk of all-cause, cardiovascular, and cancer mortality: sixteen years of follow-up in US women. Circulation. 2008; 117:1658-67.

[14] Deepa M, Farooq S, Deepa R, Manjula D, Mohan V, Prevalence and significance of generalized and central body obesity in an urban Asian Indian population in Chennai,India, Eur J ClinNutr.2009 Feb;63(2):259-67. Epub 2007 Oct 10.

[15] De Silva AP1, De Silva SH2, Haniffa R3, et al. A cross sectional survey on social, cultural and economic determinants of obesity in a low middle income setting. Int J Equity Health. 2015 Jan 17; 14:6. doi: 10.1186/s12939-015-0140-8.

[16] García-Alvarez A1, Serra-Majem L, Ribas-Barba L, et al Obesity and overweight trends in Catalonia, Spain (19922003): gender and socio-economic determinants. Public Health Nutr. 2007 Nov; 10(11A):1368-78.

[17] Hajian-Tilaki KO1, Heidari B., Prevalence of obesity, central obesity and the associated factors in urban population aged 20-70 years, in the north of Iran: a population-based study and regression approach.Obes Rev. 2007 Jan; 8(1):3-10.

[18] Deurenberg P1, Hautvast JG. Prevalence of overweight and obesity in The Netherlands in relation to sociodemographic variables, lifestyle and eating behavior: starting points for the prevention and treatment of obesity. BiblNutrDieta. 1989; (44):8-21. 